\title{
Aulas Remotas Durante a Pandemia: dificuldades e estratégias utilizadas por pais
}

\author{
Nataly Moretzsohn Silveira Simões Lunardi' \\ Andrea Nascimento \\ Jeff Barbosa de Sousa' \\ Núbia Rafaela Martins da Silva' \\ Teresa Gama Nogueira Pereira' \\ Janaína da Silva Gonçalves Fernandes" \\ 'Centro Universitário FIEO (UNIFIEO), Osasco/SP - Brasil \\ "Universidade Ibirapuera (UNIB), São Paulo/SP - Brasil
}

RESUMO - Aulas Remotas Durante a Pandemia: dificuldades e estratégias utilizadas por pais. $\mathrm{O}$ objetivo da pesquisa é compreender as representações sociais de pais sobre suas dificuldades e estratégias utilizadas nas aulas remotas oferecidas aos seus filhos. Participaram 147 pais/responsáveis de filhos em situação de ensino remoto. Para coleta dos dados, utilizou-se questionário sociodemográfico e Teste de Evocação Livre de Palavras. Os dados foram analisados por meio da análise prototípica. Os resultados apontaram dificuldades com: internet, administração do tempo, concentração e conciliação do estudo/trabalho. As estratégias adotadas foram: organização da rotina e do local de trabalho e estudo, conversas e acompanhamento das atividades dos filhos. Considerou-se que estes pais precisam de mais informação e melhor suporte escolar.

Palavras-chave: Afastamento Social. Educação. Ensino Remoto. Família. Representações sociais.

ABSTRACT - Remote Classes During the Pandemic: difficulties and strategies used by parents. The research's objective is to understand the social representations of parents about their difficulties and offered to their children. 147 parents/guardians of children in remote education participated. For data collection, a sociodemographic questionnaire and Free Word Evocation Test were used. The data were analyzed using prototypical analysis. The results showed difficulties with the internet, time management, concentration, and reconciliation of the study/work. The strategies adopted were: organization of the routine and the workplace and study, conversations, and monitoring of the children's activities. It was considered that these parents need more information and better school support.

Keywords: Social withdrawal. Education. Remote Education. Family. Social Representations.

Educação \& Realidade, Porto Alegre, v. 46, n. 2, e106662, 2021. 1

http://dx.doi.org/10.1590/2175-6236106662 


\section{Introdução}

Segundo dados da Organização Mundial da Saúde (OMS, 2021), em dezembro de 2019 o mundo foi alertado sobre vários casos de pneumonia na cidade de Wuhan, na China. No inicio de janeiro, as autoridades chinesas confirmaram que a causa seria um novo tipo de vírus, de uma família denominada de Coronavirus Disease 2019 (COVID-19).

Com a crise pandêmica global, a quarentena foi instalada mundialmente, e no Brasil não foi diferente. No mês de fevereiro, o Brasil tem o diagnóstico do primeiro caso da COVID-19 e em 17 de março o Ministério da Educação aprova a substituição das aulas presenciais por aulas remotas emergenciais com o apoio dos meios digitais devido às medidas de afastamento social declaradas em diversos Estados do país (Brasil, 2020).

O governo e a população tiveram de se enquadrar no novo ritmo de vida com a organização do Home Office, com o comércio e as escolas fechadas, estas com atividades unicamente remotas com auxílio dos professores. O deslocamento permitido era apenas emergencial (Gandra, 2020; Queiroga, 2020; Vercelli, 2020). Através da crise pandêmica houve a instauração de novas crises, sendo elas econômicas, psicológicas, educacionais e em todos os sentidos da vida, pois mudanças bruscas ocorreram (Alves, 2020).

Segundo Betto, Boff e Cortella (2018), o momento em que os indivíduos têm que viver reclusos devido à saúde ameaçada remete a um novo tipo de convivência que traz algumas mudanças e até perturbações em alguns casos. O envolvimento e desenvolvimento do papel da família em aulas remotas apresentam transformações no que se refere à atuação destes pais de maneira efetiva para que os filhos participem das aulas.

Ferreira (2020) aponta que se deve considerar positivamente a participação efetiva dos pais na vida dos filhos, que, além de possibilitar uma visibilidade maior às aulas remotas, promove algo que até o momento passava despercebido. Devido à correria do dia a dia, a maioria destes pais não tinha familiaridade com esta modalidade de ensino e, por vezes, com realidade do processo de ensino-aprendizagem de seus filhos.

Enquanto acompanhavam as aulas remotas, foram associadas reponsabilidades de cunho pedagógico a estes pais. Esta experiência oportunizou a empatia no que diz respeito à atuação do professor, ou seja, promoção de um olhar de importância ao trabalho do professor, visto que estes pais se surpreenderam e trouxeram o seguinte questionamento: como é possível dar conta de tantos alunos ao mesmo tempo? (Ferreira, 2020; Rocha, 2020).

Hodges et al (2020) explicam que o trabalho educacional remoto é um trabalho que requer paciência e ao mesmo tempo criatividade, pois, apesar de ser aplicado a distância, deveria preconizar a transmissão em tempo real das aulas, promovendo constante contato entre educador e 
estudante. A educação remota refere-se à distância espacial e o que está sendo feito atualmente é um ensino remoto de emergência, que deve ser considerado uma solução temporária para um problema imediato.

Segundo Arruda e Lima (2013), o envolvimento afetivo dos pais no acompanhamento dos filhos, além de fortalecer o vínculo, beneficia e favorece a criança em seu desenvolvimento, bem como beneficia também os pais na construção da aprendizagem do seu filho e no seu desenvolvimento enquanto sujeito. Neste contexto, os pais tiveram, de improviso, que aprender a ensinar e acompanhar os filhos, tanto no que tange ao pedagógico quanto à tecnologia, além de se adequar às aulas gravadas, vídeo conferências, enfim, às aulas remotas com atividades síncronas e assíncronas, nas quais o aluno recebe o material e em dado momento do dia acessa a aula de modo online.

No entanto, para se pensar nos pais enquanto agentes de mudanças, são necessárias reflexões que, de certa forma, multiplicam não somente as motivações ressaltadas neste estudo, mas também as motivações de conhecer o novo, e o próprio interesse nessas mudanças. No cotidiano destes pais diante da pandemia, houve grandes transformações, bem como na forma de ensinar e aprender num momento em que a vida em rede rompia a barreira da distância e a comunicação nunca mais seria como antes. Logo, houve um salto qualitativo e as aulas remotas ganharam força (Di Felice; Lemos, 2014; Calejon; Brito, 2020).

Com todos esses fatos recorrentes de uma pandemia, houve a inquietação de analisar o contexto dos pais e suas dificuldades e estratégias para lidar com as questões educacionais de seus filhos em tempos de afastamento social. Neste contexto, parte-se da hipótese de que as representações sociais que os pais têm sobre a temática apresentam algumas situações que influenciam o seu modo de pensar e vivenciar as novas tecnologias, até o momento pouco utilizadas para o ensino formal.

As representações sociais são uma modalidade de conhecimento e uma interpretação do real, determinadas pela estrutura da sociedade nas quais elas se desenvolvem (Moscovici, 2012). Jodelet (1989, p. 4-5) definiu as representações sociais como "[...] uma forma de conhecimento, socialmente elaborado e compartilhado, que tem um objetivo prático e concorre para a construção de uma realidade comum a um conjunto social".

Segundo Moscovici (2012), os indivíduos dirigem-se à nova informação e a representam buscando, ao mesmo tempo, enriquecer e transformar seus esquemas cognitivos anteriores, no que for possível e aceitável às suas idiossincrasias, como também adaptá-la aos seus antigos esquemas cognitivos, com o objetivo de manter seu mundo estável e seguro. Neste sentido, as representações sociais estão relacionadas com a criação e transformação dos valores que, consequentemente, irão influenciar as diretrizes dos relacionamentos humanos. Na forma como o indivíduo se percebe no mundo e com o outro, o que era certo para a geração anterior, para a geração atual não é, e vice versa. 
A Teoria das Representações Sociais evoluiu em três abordagens de pesquisa ao longo do tempo, sendo a sociogênica (Moscovici, 2012; Jodelet, 1989), a societal e o modelo estrutural que averigua o núcleo da representação, considerando o elemento duro como a parte resistente às mudanças e que dá coerência e sentido a uma representação; investigam-se também os elementos periféricos que protegem o núcleo. Estes dois subsistemas, central e periférico, funcionam exatamente como uma entidade, na qual cada parte tem um papel (Abric, 1998). De tal modo, a presente pesquisa está pautada nesta abordagem estrutural das representações sociais.

Conforme Abric (1998), uma representação social constitui-se como um conjunto organizado e estruturado de informações, crenças, opiniões e atitudes. As representações sociais são estruturadas em dois aspectos, isto é, toda representação possui uma imagem e uma ideia, sendo assim, tem-se a face figurativa e a face simbólica. Com isso, as representações sociais possuem funções e aplicabilidades cognitivas, permitindo a compreensão e a explicação da realidade. Elas protegem seus significados identitários, situando os grupos dentro de sua cultura específica, orientam as práticas sociais, comportamentos e condutas no grupo social e, permitem que os autores sociais expliquem e justifiquem suas posturas e condutas nos diversos espaços sociais.

Neste momento de afastamento social, as famílias dividem em casa tarefas de trabalho entre horários com outras reuniões virtuais, por também elas estarem em Home Office e ao mesmo tempo apoiarem seus filhos em atividades remotas e videoaulas educacionais. Este espaço-tempo é dividido entre a vida cotidiana do lar, da escola e do trabalho, tudo ocorrendo concomitantemente. Esta movimentação voltada a uma nova maneira de ensinar e aprender, por sua vez, pode influenciar as representações sociais destes pais e o modo de se lidar com uma nova realidade.

O objetivo desta pesquisa é compreender como se organizam as representações sociais de pais, a partir das dificuldades e estratégias utilizadas nas aulas remotas oferecidas aos seus filhos, em tempo de afastamento social. Espera-se que os resultados desta pesquisa possibilitem a reflexão sobre o tema por parte dos pais que ora exercem o papel de docentes, dos profissionais da Educação, da sociedade como um todo e também dos órgãos governamentais.

\section{Método}

A presente pesquisa foi desenvolvida com base em abordagem qualitativa, do tipo descritivo exploratório, pautada na abordagem estrutural da Teoria das Representações Sociais (Abric, 1998). O trabalho versa sobre as aulas remotas no período de pandemia, a participação da família no processo da aprendizagem e o uso de novas tecnologias como instrumento mediador. 


\section{Participantes}

O método de amostragem incluiu membros da população que estão à disposição dos pesquisadores, por conveniência, denominado Snowball. Neste método, os próprios participantes do estudo indicam participantes futuros entre seus conhecidos. A amostragem continua até a saturação dos dados, ou seja, quando os resultados coletados começam a repetir-se e tornam-se redundantes (Naderifar; Goli; Ghaljaie, 2017).

O critério para inclusão na amostra era o de serem pais/responsáveis de ambos os sexos de filhos em situação de ensino remoto. O estudo contou inicialmente com 151 pais/responsáveis participantes, porém, alguns foram excluídos da amostra, visto que responderam somente o questionário sociodemográfico e não o Teste de Evocação Livre de Palavras, totalizando-se, assim, a análise das respostas de 147 pais/responsáveis participantes. Os nomes dos participantes não foram citados no presente estudo, obedecendo, dessa forma, os procedimentos éticos estabelecidos para a pesquisa científica em Ciências Humanas.

\section{Instrumentos}

Os instrumentos utilizados foram: a) Questionário sociodemográfico, que buscou algumas variáveis, tais como: cidade em que reside, facilidade de acesso à internet, formação, sexo, Home Office atual, idade, estado civil, cor/etnia, renda familiar, número de filhos, suporte pedagógico da escola no ensino remoto, meios pedagógicos utilizados no ensino remoto; b) Teste de Evocação Livre de Palavras: é uma técnica projetiva, com o intuito de captar aspectos implícitos dos pensamentos dos respondentes. Consiste em demandar que o participante escreva 5 palavras ou expressões que lhe venham à mente após ouvir o termo indutor (Vergès, 1992). No caso da presente pesquisa, foram propostos dois termos indutores: dificuldades enfrentadas durante as aulas remotas e estratégias utilizadas durante as aulas remotas.

\section{Procedimentos de Coleta dos Dados}

O questionário sociodemográfico e o Teste de Evocação Livre de Palavras foram elaborados por meio de formulário na plataforma Google Forms. A aplicação destes instrumentos ocorreu por meio de um link que foi encaminhado por e-mail para pais/responsáveis de alunos em processo de escolarização do ensino público e privado das redes estaduais e municipais da região oeste da Grande São Paulo e de Brasília, nos diferentes níveis (Educação Infantil, Ensino Fundamental I, Ensino Fundamental II e Ensino Médio). O link que foi compartilhado e respondido ficou disponível durante o mês de maio do ano de 2020, no período de 20 dias, época em que o ensino presencial estava suspenso nas escolas brasileiras. 
Aulas Remotas Durante a Pandemia

\section{Procedimento de Análise de Dados}

Para a análise, foram considerados os dados respondidos pelos participantes, de acordo com a seguinte ordem:

1) A caracterização do grupo de pais/responsáveis ocorreu por meio da análise descritiva simples.

2) Categorização semântica: consiste em agrupar palavras ou expressões com o sentido semântico semelhante para evitar maior dispersão, como por exemplo: paciência, falta paciência, paciência para explicar as atividades que não são compreendidas. Conforme Franco (2018, p. 63) “[...] o critério de categorização também pode ser sintático (os verbos, adjetivos) ou léxico (classificação das palavras segundo seu sentido, com emparelhamento dos sinônimos e dos sentidos próximos)".

3) Após o tratamento de categorização semântica, foi realizada análise prototípica com o apoio do software Interface de $R$ pour analyses Multidimensionnelles de Textes et de Questionnaires (IRAMUTEQ) (Camargo; Justo, 2018) das palavras coletadas pelo Teste de Evocação Livre de Palavras. As respostas evocadas a partir dos termos indutores - dificuldades enfrentadas durante as aulas remotas e estratégias utilizadas durante as aulas remotas - constituíram dois corpus iniciais do material a ser analisado, que foram inseridos separadamente no software IRAMUTEQ. Depois de processados os dados, a análise prototípica apresenta a construção de quatro quadrantes, baseada no cálculo de frequências e ordens de evocação das palavras, com a finalidade de situar o grau de saliência dos elementos da representação. Estes resultados apresentam as possíveis palavras que ocupam a centralidade, a zona de contraste e as periferias na estrutura das representações sociais (Vergès, 1992).

\section{Resultados}

A pesquisa contou com uma amostra de conveniência, em que participaram 152 pais com idade entre 20 e 60 anos, com 71,05\% morando na Grande São Paulo, o restante sendo distribuídos da seguinte forma: 9,21\% no Interior de São Paulo; 15,13\% em Goiás; 0,66\% na Bahia; $0,66 \%$ no Ceará; $1,32 \%$ no Paraná; $0,66 \%$ em Pernambuco; $0,66 \%$ no Rio de Janeiro e $0,66 \%$ no Rio Grande do Sul. Desses, apenas cinco participantes não possuem internet em sua residência. Acerca da formação dos participantes, identificou-se: 1,97\% com Doutorado; 8,55\% com Mestrado; 40,13\% com Pós-graduação; 22,37\% com Ensino Superior Completo; $7,24 \%$ com Ensino Superior Incompleto; 12,50\% com Ensino Médio Completo; 1,32\% com Ensino Médio Incompleto; 3,29\% com Ensino Fundamental Completo; 2,63\% com Ensino Fundamental Incompleto. Dentre todos, $87,5 \%$ eram do sexo feminino e $12,5 \%$ do sexo masculino.

Devido ao cenário de pandemia vivido no Brasil atualmente, os pais, assim como todos os brasileiros, tiveram suas vidas afetadas pelos protocolos definidos pela OMS em 30 de janeiro de 2020, tais como o uso de máscara nos locais públicos e transportes, uso de álcool para higie- 
nizar as mãos, isolamento social, quarentena no trabalho e escola. Dos pais entrevistados, tem-se $68,42 \%$ trabalhando em Home Office contra $31,58 \%$ que disseram não trabalhar. Essas situações impostas pela doença afetam a todos sem distinção de classe social ou etnia, sendo que os menos favorecidos sofrem um impacto maior em suas vidas.

Deve-se destacar ainda nesta pesquisa os seguintes dados: $3,29 \%$ abaixo dos 30 anos; $55,26 \%$ de 30 a 40 anos; $34,87 \%$ de 41 a 50 anos; $5,26 \%$ de 51 a 60 anos; $1,32 \%$ acima de 60 anos. O estado civil dos participantes é distribuído da seguinte forma; 79,61\% são casados; 7,24\% são divorciados; 4,61\% são separados; 6,58\% são solteiros e 1,97\% não declararam estado civil. Dentre eles, tem-se $65,13 \%$ se declarando brancos; $26,32 \%$ pardos; $6,58 \%$ pretos; $1,32 \%$ amarelos e $0,66 \%$ não souberam definir.

Em relação à renda familiar, 29,61\% tem vencimentos de 1 a 3 salários; 33,55\% de 4 a 6 salários; 18,42\% de 7 a 10 salários e 18,42\% acima de 10 salários. Em relação ao número de filhos, 46,05\% informaram ter 1 filho; 44,08\% tem 2 filhos; 7,24\% tem 3 filhos; 1,97\% têm 4 filhos e 0,66\% 5 tem filhos. Diante deste cenário em casa com os filhos, estes pais sinalizaram que 9,21\% não têm suporte pedagógico; $69,08 \%$ têm suporte pedagógico e 21,71\% têm suporte pedagógico insuficiente. Quanto à plataforma oferecida para realizar estes estudos em casa pelas instituições de ensino, tem-se: $73,68 \%$ com recursos digitais; $17,76 \%$ apenas com material impresso: apostilas e livros; $0,66 \%$ não têm nenhum recurso digital oferecido e apenas 7,89\% têm os recursos digitais e materiais impressos para que seus filhos possam estudar em casa.

\section{Categorização Semântica}

Em um primeiro momento, foi realizada a revisão ortográfica e gramatical das respostas dos participantes, excluindo erros, ajustando sinais ortográficos e excluindo os espaços e sinais de pontuação, a fim de adequar o texto para análise por meio do software IRAMUTEQ.

Em sequência, a fim de facilitar e uniformizar a análise dos dados obtidos na pesquisa, considerando a intenção das respostas dos participantes, sem mudança do sentido semântico das palavras, foram realizadas algumas revisões no texto.

A palavra paciência foi mencionada 57 vezes, em alguns casos foi atrelada à questão 1 , relacionada às dificuldades enfrentadas referentes ao ensino a distância dos filhos em função do distanciamento social por conta da Covid-19: paciência, falta paciência, paciência para explicar as atividades que não são compreendidas. Na questão 2, sobre as estratégias adotadas para lidar com o problema, a palavra paciência surgiu nas seguintes frases e expressões: paciência, tentar ter paciência, treinar paciência, ser paciente, exercício da paciência, respirar fundo (neste caso optou-se por trocar para a palavra paciência para uniformizar as expressões, sem modificar seu sentido), exercer a paciência, ter paciência.

Ademais, a palavra impaciência foi mencionada 7 vezes, todas como resposta da questão 1 (relativa aos problemas enfrentados), sen- 
Aulas Remotas Durante a Pandemia

do que uma das vezes surgiu relacionada às crianças (impaciência das crianças).

Por sua vez, a palavra dedicação foi mencionada 4 vezes, sendo que 3 vezes foi como resposta às estratégias adotadas (questão 2), e somente uma das vezes relacionada à questão 1 , sobre os problemas enfrentados. Em um dos casos, a expressão veio atrelada às atividades: dedicação às atividades. Neste caso, a expressão foi resumida para dedicação, com a finalidade de uniformização das palavras.

O termo horário apareceu 12 vezes, da seguinte forma: horário, combinados de horário, disciplina nos horários, choque de horários. Exceto por esta última expressão, todos foram mencionados como estratégias adotadas (questão 2), e todos foram resumidos para horário, para fins de uniformização.

Em algumas situações, o termo horário traz o sentido mais aproximado com a palavra rotina. Por este motivo, optou-se por modificar para rotina: ter horário de estudo, horas de sono regular, horário para levantar e dormir, determinar horários, planejamento de horários e uma rotina para o estudo, organização dos horários, horário escolar, ter horário para realizar, conseguir manter um horário fixo, tentar fazer as atividades nos horários de aulas, manter o horário de escola, horário para estudar, horário escolar, estabelecer horário de estudo.

Em outras situações, o termo horário apareceu atrelado a expressões que traziam um sentido mais aproximado com outras palavras ou expressões: disciplina nos horários (foi reduzido para disciplina), conviver com as frequentes mudanças de planejamento da escola (horários, dias da semana), tempo com atividades síncronas (foi reduzido para mudanças de planejamento), trabalhar em horário que possa auxiliá-lo no acompanhamento da aula (foi reduzido para auxiliar), e cobrar horários quanto às aulas (foi reduzido para cobrança).

Com efeito, a palavra rotina foi a que mais apareceu nas respostas (80 vezes), entretanto, em muitas respostas, como nos exemplos acima, o participante não escreveu rotina, mas sim outra expressão com o mesmo sentido, sendo que, nestes casos, optou-se por reduzir para a palavra rotina para simplificar e uniformizar as respostas, facilitando a análise do corpus. Esta adequação foi feita nas seguintes hipóteses: rotina da família, hora certa para atividades, manter a rotina, está difícil manter uma rotina de trabalho, dar o café da manhã e já deixá-lo na mesa aguardando a aula, falta de rotina, ter horário de estudo, planejamento de estudo, seguir a agenda semanal e atividades, horas de sono regular, horário para levantar e dormir, rotina definida, tentar dar alguma rotina à criança, lições de casa devem ser feitas na sequência, elaboramos uma rotina diária, tentar manter a rotina, rotina para as atividades, verificar plataforma com lições de casa, uma rotina para estudar, criamos uma rotina, nas quais foram feitas adaptações para essa nova realidade de ensino. Tão longe, mas tão perto! (nesta hipótese, a palavra rotina é tão relevante quanto adaptações, por este motivo, optou-se por manter as duas palavras: adaptações e rotina), todos os dias um tempo para o 
estudo, desorganização da rotina, fizemos uma rotina e estamos tentando cumprir, realizar uma rotina de estudo, fazer as atividades e depois ver $T V$, desorganização da rotina, manter rotina de estudo, de hora em hora, e dividir as tarefas escolares no máximo de horas possivel, lição de casa logo após aula, fazer uma matéria por dia, ajustar, ter uma rotina, rotina fiel por ambas as partes, tentar fazer as atividades nos horários de aulas, criar uma rotina, fazer uma disciplina por dia e tentar dar alguma rotina à criança.

A seguir, outra palavra que apareceu muitas vezes foi tempo. Da mesma forma que as palavras anteriores, foi necessário adequá-la, visando à uniformização, sem perder o sentido da expressão e a intenção do participante. Nas 57 vezes que a palavra apareceu, 26 vezes ela apareceu isolada. Em alguns casos na questão 1, sinalizando o tempo como um problema enfrentado e, em alguns casos na questão 2, como uma estratégia para lidar com o problema. Nos demais casos, a palavra tempo foi mencionada associando-se a outras palavras. A principal delas foi falta de tempo, que apareceu 10 vezes. Nestes casos, optou-se por reduzir para tempo, visando à uniformização e simplificação para a análise do corpus. Nos demais casos, a palavra tempo foi utilizada das seguintes formas: tempo disponível, tempo de resposta, administração de tempo, falta de tempo para mim, não tenho tempo para acompanhar as atividades, tempo para os estudos, gasto todo o meu tempo em casa tentando ensiná-lo, tempo para ministrar aulas à minha filha, gestão de tempo, mesmo todos em casa, não temos tempo de ajudá-lo..., tempo disponível, organização do tempo, gestão de tempo, todo o tempo, tempo despendido prejudica o trabalho da mãe: em todos estes casos, o participante demonstrou problemas relacionados ao tempo. Por este motivo, todas as expressões foram reduzidas para tempo.

A dificuldade em conciliar atividades foi mencionada 17 vezes, na maioria das vezes relacionada à adequação da rotina de estudos dos filhos em casa com o trabalho dos pais. Contudo, cada participante respondeu com frases ou expressões diferentes, todas elas foram uniformizadas para conciliar trabalho e estudo do filho, as respostas com este sentido foram: trabalho em uma empresa onde tenho reuniões o dia todo e não consigo acompanhar minha filha nos estudos, trabalhar e também ter que coordenar o ensino a distância, dificuldade de conciliar Home Office, tempo despendido prejudica o trabalho da mãe, adequar o tempo de trabalho com as atividades escolares, não consigo ajudar e me concentrar no meu trabalho, (neste caso, a conciliação está também atrelada à concentração, entretanto, optou-se por classificar esta resposta na conciliação por ser uma expressão mais relevante para a pesquisa, pois a conciliação apareceu mais nas respostas do que a concentração). Acompanhar escola e trabalhar ao mesmo tempo, eu não fui afastada do trabalho então eles só tinham final da tarde para estudar ou só final de semana, rotina de trabalho $x$ estudo (embora a dificuldade com a rotina tenha sido mencionada nesta resposta, percebe-se que a maior dificuldade está em conciliar e não em estabelecer uma rotina), a escola está mandando muitas lições e os pais em casa estão trabalhando (esta resposta 
Aulas Remotas Durante a Pandemia

está associada também com excesso de lições da escola, entretanto, na resposta anterior este participante já havia mencionado o excesso de tarefas escolares, então, optou-se por classificar esta resposta como problemas para conciliar trabalho e estudo do filho), Não consigo ajudar e me concentrar no meu trabalho. Nos demais casos, a palavra conciliar pareceu ligada a outras expressões: conciliar diversas tarefas, conciliar a rotina de casa com o trabalho e conciliar muitas tarefas do lar e trabalho.

Problemas com internet surgiram nas respostas 17 vezes. As respostas foram uniformizadas para internet ruim e surgiram da seguinte maneira: queda de internet, pouca conexão, a internet às vezes cai, dificuldade de acesso, pois o acesso à internet às vezes falha, a internet falha, internet lenta demais, internet caindo, internet às vezes não sustenta, verificar sempre, internet lenta, quando cai o sistema por oscilações da internet, internet intermitente, falha na conexão da internet, internet de pouca qualidade, internet fraca, a internet falha, conexão caindo.

Além de problemas com internet, os participantes também demonstraram, em menor grau, problemas com computador, em algumas respostas o problema evidenciado foi a falta de computador, em outras, o problema é relacionado ao treinamento do filho ou da babá para utilizar o computador: Um computador para trabalhar e o filho estudar, tive que arranjar cinco computadores, o que não é fácil para qualquer família, computador, pois acesso as atividades pelo celular, tecnologia: ferramenta computador.

Outra dificuldade enfrentada pelos participantes foi o material enviado pela escola. As respostas sobre este tema foram uniformizadas para material ruim: horrível de enxergar as lições, material incompleto.

A palavra conhecimento, principalmente relacionada à falta de conhecimento (desconhecimento), foi mencionada oito vezes de maneiras diferentes, em alguns casos a palavra ou expressão utilizada não foi $c o$ nhecimento, mas optou-se por substituir a palavra a fim de uniformizar, sem modificar o seu sentido semântico: conhecimento, conhecimento de pedagogia infantil, muitas coisas não sei, não saber como fazer a atividade, diferença do ensino da minha época para agora, falta de conhecimento, buscar conhecimento.

A insegurança foi um sentimento mencionado também de diversas formas, tendo surgido sete vezes, em somente um caso a palavra foi usada de forma não isolada: insegurança em saber o limite do quanto uma mãe pode interferir no processo das aulas, nos demais casos os participantes responderam isoladamente insegurança ou inseguranças.

A palavra cobrança surgiu também nas respostas sete vezes, as respostas em que a palavra cobrança (ou cobranças) não veio de forma isolada foram uniformizadas para cobrança, nos seguintes casos: cobrança das lições, cobranças sem explicação das matérias, cobrando atividades lembrando o que tem que fazer etc. e cobrar horários quanto às aulas.

A palavra autonomia também fez parte dos problemas e das estratégias adotadas pelos participantes, ela surgiu nas seguintes formas: 
estímulo à autonomia, fazê-la assumir as responsabilidades pelas lições de casa, autonomia dos filhos, autonomia das crianças, ele está se virando, poucas vezes temos tempo de ajudá-lo. Nos demais casos, a palavra apareceu isolada.

A leitura também fez parte das atividades dos participantes, tendo surgido a palavra oito vezes, na maioria delas de forma isolada, entretanto, em alguns casos, a palavra veio associada a: leitura do material, livros e histórias, cálculos e leitura no dia a dia e leitura de livros bem básicos e lentamente.

A ajuda aos filhos foi evidenciada de diversas maneiras, todas as respostas que, de alguma forma, trouxeram este significado, foram uniformizadas para ajuda. No total, a ajuda surgiu em 16 situações, como nos seguintes casos: ajudo, ajuda, ajudar, eu ajudo meu filho da $2^{a}$ serie quando está tudo tranquilo, nem sempre consigo ajudar, ajudar na medida do possível, desenvolvemos juntas algumas atividades propostas pelos professores, estamos tentando ajudar, mas está difícil, ficar à disposição para dúvidas, ajudar nas atividades, estudar junto e problematizar para os filhos responderem.

Problemas relacionados ao conteúdo escolar, como uma crítica às escolas, foram destacados pelos participantes nas seguintes expressões: conteúdo interativo, muito conteúdo, o conteúdo muitas vezes é superficial, falta de aprofundar conteúdo, o colégio é muito conteudista, tema fora de contexto, conteúdo mais avançado do dia a dia da escola, conteúdo da disciplina, conteúdo superficial, conteúdo inapropriado à série ou ano dos meus filhos. No total, os problemas com conteúdo escolar forma mencionados 15 vezes. Todos foram uniformizados para conteúdo.

A palavra atenção foi mencionada pelos participantes 15 vezes, em sua maioria de forma isolada, entretanto, em alguns casos a palavra atenção veio acompanhada de uma frase ou expressão, nestes casos, a resposta foi uniformizada para atenção: fazer a criança prestar atenção, meus filhos de 8 e 10 anos nunca ficam as 5h de aula prestando atenção, falta de atenção da criança, atenção para todos, ter atenção.

Contudo, a palavra concentração, que surgiu 22 vezes, em sua maioria relacionada com a falta de atenção, por este motivo, em alguns casos optou-se por centralizar a expressão ou frase em concentração e não em atenção, pois nestes casos o maior peso da resposta está relacionado à concentração. $\mathrm{O}$ termo concentração surgiu ou foi escolhido por seu sentido nos seguintes casos: falta de concentração, concentração dos pequenos, eles não conseguem se concentrar, concentração da parte deles, falta de atenção para assistir a aula, manter a atenção, prender a atenção dele nas aulas online, as crianças ficam meios dispersas dessa forma, dificuldade de concentração na aula, eles não conseguem se concentrar, concentração nas aulas, falta de atenção da criança.

As brincadeiras também foram estratégias adotadas pelos pais na pandemia, a palavra surgiu 11 vezes e foi uniformizada para brincadeiras nas seguintes frases ou expressões: brincadeiras lúdicas, mais brincadeiras, brincadeiras no quintal, crianças na escola aprendem brin- 
cando (neste caso, surgiu como um problema relacionado à falta de brincadeiras), procurar variar atividades com brincadeiras e interagir com brincadeiras e jogos.

Como forma de ajudar os filhos, os pais utilizaram-se da pesquisa. Foram 10 aparições da palavra. A palavra, além de ter sido utilizada de forma isolada, surgiu associada a: pesquisa de atividades pedagógicas extras, pesquisa de determinados assuntos para elucidação, pesquisa na internet sobre assuntos da matéria, buscar fonte de pesquisa, pesquisar na internet para poder ajudá-lo, pesquisar antes de ajudar.

A palavra participar surgiu em diversas vezes. Algumas vezes com o sentido parecido com o da palavra acompanhar. Nas seguintes expressões a palavra participar teve mais relevância, então foram uniformizadas para participar: participar das aulas junto, participar das aulas esclarecendo suas dúvidas, procuro participar de algumas aulas com a minha filha, participar das aulas esclarecendo suas dúvidas.

Por sua vez, a palavra acompanhar surgiu 19 vezes e foi mais relevante em: posso acompanhá-la, acompanhar as tarefas, tentar acompanhar as aulas on-line, acompanhar as aulas, acompanhamento, acompanhar as atividades, acompanhar eles em todas as atividades, acompanhar à distância, acompanhar literalmente as aulas, tenho tentado acompanhar da melhor forma, mas na medida do possivel estou acompanhando, acompanhar os estudos da criança.

A palavra cansaço foi mencionada pelos participantes 9 vezes: cansaço pelo acúmulo de atribuições (paternidade, trabalho, estudo, casa), pais cansados, cansaço paternal, nestes casos a expressão ou frase foi resumida para cansaço. Nas demais menções, a palavra foi mencionada de forma isolada.

O suporte escolar também foi mencionado nas respostas (9 vezes). Em algumas respostas veio atrelada à falta de suporte, como um problema enfrentado: falta de apoio da escola, poucas informações por parte dos professores, comunicação com o colégio, falta de suporte da escola, falta de apoio da instituição educacional, falta de suporte adequado, falta de orientação pedagógica ou capacitação dos pais. Em outras respostas, o suporte escolar surgiu como uma estratégia adotada para lidar com o os problemas: manter contato com os professores, contato com os professores, enviar dificuldades aos professores, parceria com os professores.

Priorizar também foi uma forma de uniformizar expressões ou frases (8 vezes): satisfação prioritária das necessidades primárias, faz o que der, o mais importante primeiro, tentar fazer ao menos as atividades mais relevantes, uma atividade por vez, deixar meu trabalho de lado, manter a calma e saber que é impossivel fazer tudo (neste caso, manter a calma tem a mesma relevância, por este motivo, ambas as respostas foram consideradas), tentar fazer ao menos as atividades mais relevantes, quando não dá não faz.

Os problemas relacionados ao foco surgiram 10 vezes nas respostas, nas vezes em que a palavra não surgiu isolada, ela surgiu nas seguintes respostas: fazer com que ele foque na aula, dosar brincar e tare- 
fas estando em mesmo ambiente, foco nas tarefas, eles não focavam, quer ficar brincando. Em todos estes casos, as frases foram substituídas por foco.

\section{Análise Prototípica}

A partir do termo indutor dificuldades durante aulas remotas, identificaram-se 314 palavras diferentes que foram evocadas pelos participantes. Foi considerada a frequência média de $11,14 \%$ e ordem média das evocações (OME) de 2,6 com frequência mínima 5. Logo, as palavras com frequência mínima de evocação inferior a 5 foram classificadas como tendo baixa ordem de evocação e não foram incluídas nos quadrantes da casa de quatro casas. A Tabela 1 apresenta os resultados da análise prototípica:

Tabela 1 - Análise Prototípica Referente ao Termo Indutor Dificuldades Enfrentadas Durante as Aulas Remotas (N=147)

\begin{tabular}{|c|c|c|c|c|c|c|}
\hline \multirow{3}{*}{$\begin{array}{c}\text { Frequência } \\
\text { media }\end{array}$} & \multicolumn{3}{|c|}{$\mathrm{OME} \leq 2.6$} & \multicolumn{3}{|c|}{$\mathrm{OME}>2.6$} \\
\hline & \multicolumn{6}{|c|}{ SITUAÇÃO NORMAL } \\
\hline & Elementos Centrais & $f$ & OME & $\begin{array}{c}\text { Elementos da } 1^{a} \\
\text { Periferia }\end{array}$ & $f$ & OME \\
\hline \multirow{15}{*}{ 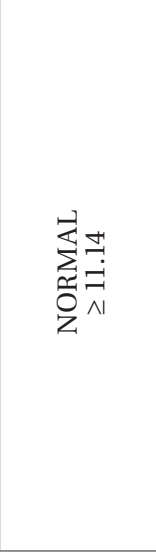 } & Tempo & 39 & 2,00 & Paciência & 23 & 2,70 \\
\hline & Concentração & 16 & 1,90 & Rotina & 15 & 3,10 \\
\hline & Internet ruim & 15 & 1,90 & Sociabilidade & 13 & 3,20 \\
\hline & $\begin{array}{l}\text { Conciliar trabalho } \\
\text { e estudo do filho }\end{array}$ & 13 & 1,90 & & & \\
\hline & $\begin{array}{c}\text { Elementos de Con- } \\
\text { traste }\end{array}$ & $\mathrm{f}$ & OME & $\begin{array}{c}\text { Elementos da } 2^{a} \\
\text { Periferia }\end{array}$ & f & OME \\
\hline & Dúvidas & 7 & 2,40 & Medo & 10 & 3,60 \\
\hline & Insegurança & 6 & 2,00 & Cansaço & 10 & 3,30 \\
\hline & Acompanhar & 6 & 1,70 & Ansiedade & 9 & 2,80 \\
\hline & Disciplina & 6 & 2,00 & Atenção & 8 & 3,00 \\
\hline & & & & Impaciência & 7 & 3,10 \\
\hline & & & & Foco & 7 & 3,10 \\
\hline & & & & Organização & 7 & 3,00 \\
\hline & & & & Falta de material & 6 & 4,30 \\
\hline & & & & Aprendizado & 6 & 3,30 \\
\hline & & & & Interesse & 5 & 3,20 \\
\hline
\end{tabular}

Legenda: $\mathrm{f}=$ frequência; OME- ordem média de evocações. Fonte: Elaborada a partir dos resultados organizados pelo software Iramuteq.

A partir dos resultados das evocações livres de palavras apresentados na Tabela 1, é possível compreender como se organizam as representações sociais dos participantes da pesquisa sobre aulas remotas. Conforme Abric (1998), a compreensão das representações sociais remete à interpretação dos comportamentos e práticas sociais que podem estar organizadas na estrutura ao redor de um núcleo central e um sistema periférico.

No primeiro quadrante superior esquerdo, podem-se observar os elementos que tiveram maior predominância na evocação dos participantes e fazem parte de um provável núcleo central das representações 
sociais do termo indutor. O elemento tempo apresentou maior frequência e maior ordem de importância no primeiro quadrante superior esquerdo.

Os elementos centrais de uma representação social geram significados, estabelecem uma organização e podem ainda disponibilizar estabilidade e continuidade à representação (Abric, 1998). Logo, os participantes trazem elementos representacionais negativos a respeito das aulas remotas que apontam a necessidade de ter concentração, mas a internet ruim e as dificuldades de conciliar trabalho e estudo dos filhos podem atrapalhar este processo.

Abric (1998) aponta que tais representações apresentam a dimensão sociocognitiva vivenciada por estes participantes em condição de afastamento social devido à pandemia ocasionada pela COVID-19. Estas representações sociais explicam que o fator tempo foi um desafio enfrentado por estes pais no acompanhamento das aulas remotas de seus filhos.

A ocorrência de fechamento de escolas e a prática do ensino remoto apresentaram uma luta para equilibrar responsabilidades concorrentes com os recursos limitados de tempo e energia. A organização do tempo do cotidiano familiar tornou-se tarefa de difícil conciliação, visto que todos os membros da família passaram a realizar suas demandas de trabalho e estudos num único ambiente, que por vezes os horários podem colidir aos interesses e obrigações individuais. No que diz respeito à duração de tempo das aulas remotas, Barbosa, Viegas e Batista (2020) ressaltam que, na percepção de professores, não houve redução de tempo em comparação às aulas presenciais, e sim uma menor participação dos alunos.

Deve-se destacar o sistema periférico que se organiza ao redor do núcleo central, responsável pela atualização e contextualização da representação. No quadrante superior direito, apresentam-se elementos da periferia próximos das representações sociais e referem-se à assimilação de novos conceitos, ainda não totalmente incorporados ao núcleo central, mas indicando uma possibilidade de inovação das opiniões e crenças. Convém destacar que ocorrem mudanças devido a esta periferia ser estável e trazer influências no núcleo central (Abric, 1998).

O elemento mais frequente da primeira periferia é paciência e o elemento sociabilidade apresentou a maior ordem de importância. Os participantes evocam que para incidir mudanças nas práticas sociais, ou seja, para que ocorra a sociabilidade, é necessário paciência com a nova rotina das aulas remotas. Pautados na Pedagogia Social, Berg, Vestena e Costa-Lobo (2020) recomendam neste caso paciência, cooperação e flexibilidade cognitiva para o desenvolvimento da autonomia e da criatividade, para ser possível promover redes de suporte aos alunos, pais e professores, diante das fragilidades decorrentes do ensino remoto emergencial em tempos de pandemia.

O quadrante inferior esquerdo, também denominado de zona contraste, é composto de elementos que tiveram baixa frequência de 
evocação, mas que foram considerados importantes, pois foram prontamente evocados. Neste quadrante, o elemento mais frequente e com maior ordem de importância foi dúvidas. Logo, embatendo com o núcleo central, um grupo menor de participantes destaca que suas dúvidas a respeito das aulas remotas estão pautadas em suas inseguranças em acompanhar as disciplinas de seus filhos.

A responsabilidade pela educação dos filhos remete inicialmente à família e, neste contexto, a escola predispõe a um ambiente de ensino-aprendizagem. Vários pais não possuem formação pedagógica para mediarem conteúdos de disciplinas de conhecimentos específicos. Além de suas demandas de trabalho, este grupo de pais se percebe sobrecarregado no acompanhamento das atividades escolares de seus filhos (Marques; Fraguas, 2020). De tal modo, as lutas para equilibrar as demandas de emprego dos pais à necessidade de ajudar seus filhos em casa com a aprendizagem escolar fez embate com pais oprimidos e com falta de equilíbrio pessoal, devido ao cenário pandêmico.

No quadrante inferior direito, denominado segunda periferia, pode-se identificar elementos mais distantes do provável eixo central das representações sociais. Neste quadrante, houve maiores frequências em vários elementos, mas o elemento menos citado foi interesse e o que apresentou menor ordem de importância foi ansiedade. Os elementos evocados pelos participantes neste último quadrante apontam que o medo, o cansaço, a ansiedade, a impaciência e a falta de material foram elementos presentes durante o período que os pais tentaram uma organização para promover a atenção, o foco e o interesse de seus filhos para o aprendizado.

Borloti et al (2020) alertam sobre a urgência de se considerar o impacto do cenário de afastamento social devido à pandemia do COVID-19 na saúde mental da população. Neste sentido, colocam-se o estresse pós-traumático e a desregulação emocional, relacionadas à ansiedade, raiva e depressão como sintomas comuns neste cenário. Conforme Abric (1998), o que nos interessa perceber neste último quadrante (segunda periferia) são os elementos menos citados e mais distantes de fazer parte do núcleo central. Seriam aqueles elementos que precisariam ser mais bem pesquisados e aprofundados para se compreender o motivo de serem pouco mencionados pelos participantes. Neste sentido, os elementos interesse e ansiedade apresentam-se como candidatos para futuras investigações.

A partir do termo indutor estratégias utilizadas durante aulas remotas, identificaram-se 333 palavras diferentes que foram evocadas pelos participantes. Foi considerada a frequência média de 11,95 \% e ordem média das evocações (OME) de 2,45 com frequência mínima 5. Logo, as palavras com frequência mínima de evocação inferior a 5 foram classificadas como tendo baixa ordem de evocação e não foram incluídas nos quadrantes da casa de quatro casas. A Tabela 2 apresenta os resultados da análise prototípica: 
Aulas Remotas Durante a Pandemia

Tabela 2 - Análise Prototípica Referente ao Termo Indutor Estratégias Utilizadas Durante as Aulas Remotas (N=147)

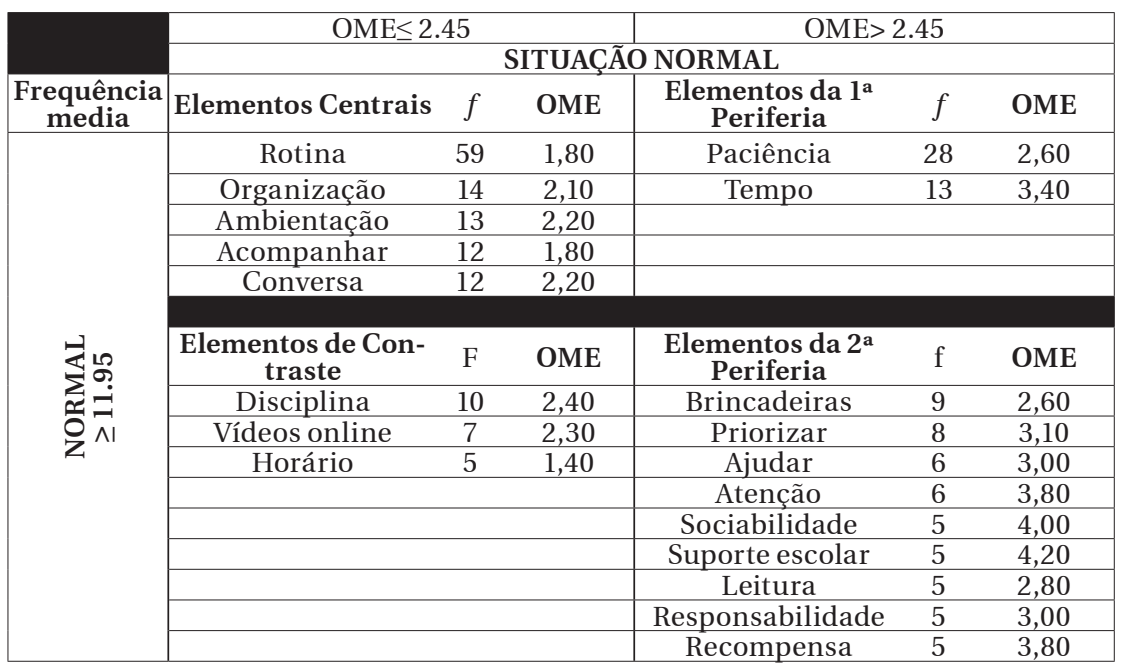

Legenda: f= frequência; OME- ordem média de evocações. Fonte: Elaborada a partir dos resultados organizados pelo software Iramuteq.

A partir dos resultados das evocações livres de palavras apresentados na Tabela 2, é possível compreender como se organizam as representações sociais dos participantes da pesquisa sobre as estratégias adotadas para enfrentar as dificuldades relacionadas com as aulas remotas.

No primeiro quadrante superior esquerdo, podem-se observar os elementos que tiveram maior predominância na evocação dos participantes sobre esta questão e fazem parte de um provável núcleo central das representações sociais do termo indutor. O elemento rotina apresentou maior frequência no primeiro quadrante superior esquerdo.

Não restam dúvidas de que o impacto causado pela pandemia da COVID-19 na sociedade gera mudanças na rotina dos indivíduos evolvidos. Contudo, a palavra rotina surgiu nos dois momentos da pesquisa, tanto como uma dificuldade enfrentada (Tabela 1, quadrante superior direito), quanto como uma estratégia adotada para enfrentar as dificuldades. A rotina impacta fortemente na vida das pessoas pelo aspecto ligado à mudança no comportamento provocada pela nova rotina e, também, como uma forma de se organizar para possibilitar a realização das atividades propostas no isolamento social.

As mudanças no estilo de vida são recomendadas no enfrentamento da pandemia. Pequenas mudanças na rotina podem auxiliar, como dar autonomia para as crianças e ensiná-las a ter responsabilidades por tarefas domésticas (Queiroga, 2020). A organização vem associada à rotina como uma segunda estratégia mais adotada pelos participantes, aparecendo como um elemento central de segunda frequência, sua relevância é destacada por ter apresentado maior ordem de impor- 
tância do que a palavra rotina. A ambientação e a conversa são elementos do núcleo central que, embora menos frequentes, trazem a maior ordem de importância do que os elementos rotina e organização.

As crianças e adolescentes vêm resistindo à rotina, pois acreditam que estão de férias, já que estão em casa, esta situação tem gerado estresse para eles e seus pais; os pais se sentem impotentes frente a este quadro, especialmente no que se refere à ausência, muitas vezes, de um espaço específico para os estudantes realizarem as tarefas e participarem das interações virtuais de forma privada, visto que a família está em casa todo o tempo (Alves, 2020).

Desta maneira, é possível destacar que organizar-se em relação à rotina e ao ambiente, bem como à conversa são os elementos representacionais principais que auxiliam os pais a lidar com o ensino a distância do filho, em função do distanciamento físico social por conta da COVID-19.

Em relação à conversa, esta é de crucial importância, visto que o entendimento e a informação sobre a pandemia são fatores que ajudam as famílias a se organizar e diminuir o estresse diário. Entretanto, os pais nem sempre estão preparados para orientar seus filhos, pois eles também precisam ser orientados (Fegert et al, 2020), podendo exercer este papel de orientação dos pais a própria escola, o hospital (caso haja hospitalização) e, também, os órgãos públicos responsáveis.

A evocação suporte escolar, como uma das estratégias adotadas no enfrentamento das dificuldades relacionadas ao ensino a distância pelos pais surgiu no quadrante inferior direito, que é aquele que tem maior distância do núcleo central. Contudo, o suporte escolar foi a evocação com maior ordem de importância no quesito de ordem de evocações. Dessa forma, buscar o suporte escolar surge para uma estratégia importante.

A escola pode fornecer informações que auxiliam os pais na tarefa de gerenciar o estudo a distância dos filhos. Estas informações podem incluir dicas para os pais sobre como conversar com crianças e adolescentes sobre a COVID-19, os riscos associados e as mudanças na vida cotidiana. Além disso, informações sobre como gerenciar a vida cotidiana em casa durante a quarentena e o distanciamento social, bem como sobre o ensino a distância, podem ser úteis (Fegert et al, 2020).

Estas representações têm apoio nas estratégias práticas de baixa evocação, ou seja, respostas destacadas por um grupo menor de participantes, como disciplina, vídeos online e horário, sendo disciplina o elemento mais frequente e com maior ordem de importância. Dessa forma, o quadrante inferior esquerdo, também denominado de zona contraste, é composto de elementos que tiveram baixa frequência de evocação, mas que foram considerados importantes, pois foram prontamente evocados.

Neste quadrante, o segundo elemento mais frequente foi vídeos online. Vale mencionar que a internet representa um instrumento de grande importância nas evocações, pois na pergunta sobre as dificul- 
Aulas Remotas Durante a Pandemia

dades enfrentadas a expressão internet ruim apareceu como elemento central, e nas estratégias adotadas (pergunta 2), a utilização de vídeos online surgiu com grande ordem de importância, embora esteja enquadrada no quadrante dos elementos de contraste com baixa frequência de evocações.

O uso da internet para o ensino a distância se caracterizou como uma estratégia muito pertinente para a continuidade dos estudos de adolescentes e adultos, não obstante incorra em graves limitações quanto à sua aplicação para crianças em função das dificuldades de se aplicar currículos online (Senhoras, 2020), especialmente no âmbito das escolas públicas ou mesmo das particulares que atingem a população de baixa renda. Neste sentido, compreende-se que há barreiras que impedem os alunos de se envolverem totalmente com as oportunidades de aprendizagem remota, tais como: necessidades educacionais especiais do aluno, a falta de conhecimento dos pais do conteúdo pedagógico, necessidade de melhor comunicação com o professor, falta de acesso às tecnologias digitais e qualidade da internet.

Contudo, na educação informal, as plataformas educativas online se tornaram, em um contexto pandêmico da COVID-19, uma oportunidade para a atualização de conhecimentos de professores, alunos e pais ou para a continuidade de estudos na ausência de aulas presenciais (Senhoras, 2020).

Conforme explicado na análise de resultado da primeira pergunta, sobre as dificuldades enfrentadas, o sistema periférico é responsável pela atualização e contextualização da representação. No quadrante superior direito, constituem a periferia próxima das representações sociais e referem-se à assimilação de novos conceitos, ainda não totalmente incorporados ao núcleo central, mas indicando uma possibilidade de inovação das opiniões e crenças. Convém destacar que ocorrem mudanças devido a esta periferia ser estável e trazer influências no núcleo central (Abric, 1998).

Sob esta ótica, o elemento mais frequente da primeira periferia é paciência, e o elemento tempo apresentou a maior ordem de importância. Os participantes evocam que para organizar a rotina, o ambiente, com acompanhamento e conversa, é necessário ter paciência e tempo.

No quadrante inferior direito, denominado segunda periferia, pode-se identificar elementos mais distantes do provável eixo central das representações sociais. Neste quadrante, houve maiores frequências em vários elementos, mas os elementos menos citados foram sociabilidade, suporte escolar, leitura, responsabilidade e recompensa e o que apresentou menor ordem de importância foi brincadeiras que, por sua vez, foi o mais frequente. Os elementos evocados pelos participantes neste último quadrante apontam que propor aos filhos brincadeiras, ajudar e dar atenção, além de priorizar as atividades, foram elementos presentes que ajudaram os pais a se adequarem à rotina e a organizarem-se melhor, facilitando o enfrentamento da pandemia.

A pandemia e o distanciamento social trouxeram nova dinâmica às famílias que possuem crianças e adolescentes em casa estudando a 
distância, o que permite refletir sobre as mutações das representações da infância na Educação, à luz desta nova realidade (Custódio, 2017). Entretanto, é possível identificar, por meio das representações sociais dos participantes, que, apesar de dificuldades principalmente relacionadas à falta de estrutura ligada ao ambiente e à internet, os pais têm utilizado estratégias como organização da rotina, do tempo, a conversa e acompanhamento dos filhos, facilitando a rápida adaptação aos novos tempos.

\section{Considerações}

O presente artigo se propôs a compreender como se organizam as representações sociais de pais sobre suas dificuldades e estratégias utilizadas nas aulas remotas oferecidas aos seus filhos, em tempo de distanciamento social. Sabe-se que, em meados de 2020, iniciou-se no Brasil um movimento de afastamento social como estratégia para combater ou ao menos diminuir a disseminação da COVID-19. Na época que este estudo foi conduzido, escolas no Brasil fecharam suas portas e passaram a recorrer ao ensino remoto emergencial. Este estágio inicial e caótico também pode ter afetado as representações sociais dos pais sobre o ensino remoto, devido ao aumento das responsabilidades.

Assim, logo nos primeiros dias foram identificados diversos problemas relacionados à educação, desde a falta de estrutura das famílias, em especial das mais pobres, até o descontrole emocional das pessoas relacionado ao isolamento e maior convivência familiar. Com isto, surgiu a necessidade, no campo da ciência, de estudar, de forma mais aprofundada a questão a fim de identificar os problemas enfrentados pelas famílias, suas causas e as estratégias adotadas por elas para lidar com a nova realidade.

As respostas oferecidas pelos participantes demonstraram que, embora sejam muitas as dificuldades enfrentadas no atual período, as famílias recorreram à criatividade e demonstraram grande poder de adaptação para enfrentar a situação. Destaca-se que as representações sociais relacionadas aos problemas enfrentados se referem à administração do tempo, à concentração no trabalho e estudos, à internet ruim e a conciliar o estudo do filho com o trabalho. As estratégias adotadas para lidar com estes problemas são a organização da rotina, melhor ambientação do local de trabalho e estudo, a conversa a fim de melhor informar os filhos e o acompanhamento deles em suas atividades.

Entretanto, identificou-se também que os pais têm grande necessidade de mais informação e melhor suporte escolar, além da questão da dificuldade financeira ser um fator importante tanto pelo aumento de custos por estarem todos em casa, como para a aquisição de novos equipamentos para adequar o estudo por meio de computadores e celulares.

A contribuição do presente trabalho está em identificar com mais precisão estas necessidades e ajudar as escolas, hospitais e órgãos res- 
ponsáveis a oferecer suporte e informação, além de prestar seus serviços com mais qualidade e foco, com o objetivo de atender as famílias naquilo que elas mais necessitam. Vale salientar que as representações sociais aqui identificadas foram colhidas de modo genérico, ou seja, sem induzir o participante a relatar suas dificuldades de modo mais específico, como, por exemplo, no campo exclusivamente psicológico ou financeiro.

Há outros campos que também podem ser explorados quanto à situação do atual distanciamento social. Esta exploração ou aprofundamento é de extrema importância para o melhor entendimento do que representa o presente momento, que é único, e demanda ações práticas por meio de políticas públicas e decisões acadêmicas por parte das escolas. Tais políticas terão maior chance de êxito, caso evidenciem preocupação pela busca de embasamento científico adequado. Dessa forma, as investigações sobre o tema devem ter continuidade.

Recebido em 20 de agosto de 2020 Aprovado em 19 de janeiro de 2021

\section{Referências}

ABRIC, Jean-Claude. A Abordagem Estrutural das Representações Sociais. In: MOREIRA, Antonia Silva Paredes; OLIVEIRA, Denise Cristina de (Org.). Estudos Interdisciplinares de Representação Social. Goiânia: Editora: AB; Edição: 2, 1998. P. 27-38

ALVES, Lynn. Educação Remota: entre a ilusão e a realidade. Interfaces Científicas: educação, Aracaju, v. 8, n. 3, p. 348-365, jun. 2020.

ARRUDA, Sérgio Luiz Saboya; LIMA, Manuela Caroline Ferreira. The New Place of the Father as Caregiver of the Child. Estudos Interdisciplinares em Psicologia, Londrina, v. 4, n. 2, p. 201-216, dez. 2013.

BARBOSA, Andre Machado; VIEGAS, Marco Antônio Serra; BATISTA, Regina Lucia Napolitano Felício Felix. Aulas Presenciais em Tempos de Pandemia: relatos de experiências de professores do nível superior sobre as aulas remotas. Revista Augustus, Rio de Janeiro, v. 25, n. 51, p. 255-280, jul./out. 2020.

BERG, Juliana; VESTENA, Carla Luciane Blum; COSTA-LOBO, Cristina. Criatividade e Autonomia em Tempo de Pandemia: ensaio teórico a partir da pedagogia social. Revista Internacional de Educación para la Justicia Social, Madri, v. 9, n. 3, maio 2020.

BETTO, Frei; BOFF, Leonardo; CORTELLA, Mario Sergio. Felicidade Foi-se Embora? Petrópolis: Editora Vozes Limitada, 2018.

BORLOTI, Elizeu et al. Saúde Mental e Intervenções Psicológicas Durante a Pandemia da COVID-19: um panorama. Revista Brasileira de Análise do Comportamento, Belém, v. 16, n. 1, p. 21-30, jun. 2020.

BRASIL. Portaria no 343 , de 17 de março de 2020. Dispõe sobre a Substituição das Aulas Presenciais por Aulas em Meios Digitais Enquanto Durar a Situação de Pandemia do Novo Coronavírus - COVID-19. Ministério da Educação, 2020. Disponível em: <http://www.in.gov.br/en/web/dou/-/portaria-n-343-de-17-demarco-de-2020-248564376>. Acesso em: 03 jun. 2020. 
CALEJON, Laura Marisa Carnielo; BRITO, Alan de Santana. Entre a Pandemia e o Pandemônio: uma reflexão no campo da educação. Educamazônia: educação, sociedade e meio ambiente, Humaitá, v. 25, n. 2, p. 291-311, jul./dez. 2020.

CAMARGO, Brígido Vizeu; JUSTO, Ana Maria. Tutorial para Uso do Software IRAMUTEQ [Internet]. Porto Alegre: UFSC, 2018. Disponível em: $<$ http://iramuteq.org/documentation/fichiers/tutoriel-portugais-22-11-2018>. Acesso em: 18 jan. 2021.

CUSTÓDIO, Crislei de Oliveira. Representações da Infância nos Discursos Pedagógicos: mutações e temporalidades. Educação \& Realidade, Porto Alegre, v. 42, n. 1, p. 299-321, jan./mar. 2017.

DI FELICE, Massimo; LEMOS, Ronaldo. A Vida em Rede. Campinas: Papirus, 2014.

FEGERT, Jörg et al. Challenges and Burden of the Coronavirus 2019 (COVID-19) Pandemic for Child and Adolescent Mental Health: a narrative review to highlight clinical and research needs in the acute phase and the long return to normality. Child and Adolescent Psychiatry and Mental Health, Germany, v. 14, p. 1-11, may 2020.

FERREIRA, Patrícia Tocha. Uma Realidade das Escolas Particulares Perante a Pandemia da COVID-19. Revista Gestão \& Tecnologia, Goiânia, v. 1, n. 30, p. 3840, jan./jun. 2020.

FRANCO, Maria Laura Puglisi Barbosa. Análise de Conteúdo. 5ª edição. Campinas: Editora Autores Associados, 2018.

GANDRA, Alana. Empresas Adotam Home-Office por Conta do Coronavirus. Rio de Janeiro: Agência Brasil, mar. 2020. Disponível em: <https://agenciabrasil. ebc.com.br/saude/noticia/2020-03/empresas-adotam-home-office-por-contado-coronavirus>. Acesso em: 14 jul. 2020.

HODGES, Charles et al. As Diferenças entre o Aprendizado Online e o Ensino Remoto de Emergência. Revista da Escola, Professor, Educação e Tecnologia, Recife, v. 2, p. 1-12, abr. 2020.

JODELET, Denise. Représentations Sociales: um domaine en expansion. Tradução: Tarso Bonilha Mazzotti. In: JODELET, Denise (Ed.) Les Représentations Sociales. Paris: PUF, 1989. P. 31-61.

MARQUES, Ronualdo; FRAGUAS, Talita. A Ressignificação da Educação: virtualização de emergência no contexto de pandemia da COVID-19. Brazilian Journal of Development, Curitiba, v. 6, n. 11, p. 86159-86174, nov. 2020.

MOSCOVICI, Serge. Representações Sociais: investigações em psicologia social. Tradução: Pedrinho Arcides Guareschi. Petrópolis: Vozes, 2012.

NADERIFAR, Mahin; GOLI, Hamideh; GHALJAIE, Fereshteh. Snowball Sampling: a purposeful method of sampling in qualitative research. Strides in Development of Medical Education, Kerman, v. 14, n. 3, p. 1-6, sep. 2017.

OMS, Organização Mundial da Saúde. Folha informativa COVID-19: escritório da OPAS e da OMS no Brasil. jan. 2021. Disponível em: <https://www.paho.org/ pt/covid19>. Acesso em: 18 jan. 2021.

QUEIROGA, Fabiana. Orientações para o Home Office Durante a Pandemia da Covid-19. Porto Alegre: Artmed, 2020.

ROCHA, Daniel dos Santos. Readequação do Contexto Escolar para o Formato Remoto Em Meio à Pandemia de COVID-19. Pedagogia em Ação, Belo Horizonte, v. 13, n. 1, p. 263-274, jul. 2020. 
SENHORAS, Eloi Martins. Coronavírus e Educação: análise dos impactos assimétricos. Boletim de Conjuntura (BOCA), Boa Vista, v. 2, n. 5, p. 128-136, maio 2020 .

VERCELLI, Ligia de Carvalho Abões. Aulas Remotas em Tempos de COVID-19: a percepção de discentes de um programa de mestrado profissional em educação. Revista @mbienteeducação, São Paulo, v. 13, n. 2, p. 47-60, maio/ago. 2020. VERGĖS, Pierre. L'Evocation de L'Argent: une méthode pour ladéfinition du noyau central d'une représentation. Bulletin de psychologie, Paris, v. 45, n. 405, p. 203-209, jan./fév. 1992.

Nataly Moretzsohn Silveira Simões Lunardi é doutoranda em Psicologia Educacional. Mestre em Direitos Fundamentais.

ORCID: http://orcid.org/0000-0001-7802-2363

E-mail: professoranataly@gmail.com

Andrea Nascimento é doutoranda em Saúde Pública - UCES e mestranda em Psicologia Educacional - UNIFIEO.

ORCID: http://orcid.org/0000-0003-4171-2074

E-mail: andrea.nasci@hotmail.com

Jeff Barbosa de Sousa é mestrando em Psicologia Educacional.

ORCID: http://orcid.org/0000-0002-7352-0301

E-mail: jeff.souza@unifieo.br

Núbia Rafaela Martins da Silva é mestranda em Psicologia Educacional. ORCID: http://orcid.org/0000-0003-0154-7895

E-mail: nubiasophia2014@gmail.com

Teresa Gama Nogueira Pereira é doutoranda em Psicologia Educacional. ORCID: http://orcid.org/0000-0002-5749-211X

E-mail: teresa.gamma@yahoo.com.br

Janaína da Silva Gonçalves Fernandes é doutora e Mestre em Psicologia Educacional. Professora do Programa Stricto Sensu em Educação UNIB ORCID: http://orcid.org/0000-0001-6621-9185

E-mail: janainagoncalves80@yahoo.com.br

Editora-responsável: Beatriz Vargas Dorneles

Este é um artigo de acesso aberto distribuído sob os termos de uma Licença Creative Commons Atribuição 4.0 Internacional. Disponível em: <http:// creativecommons.org/licenses/by/4.0>. 